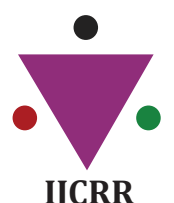

IJCRR

Section: Healthcare

Sci. Journal Impact

Factor: 6.1 (2018)

ICV: 90.90 (2018)

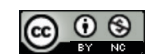

Copyright@IJCRR

\section{Study of Cardiovascular Risk Prediction in Patients with Type 2 Diabetes with Arterial Hypertension after Combined Hypotensive Therapy of Enalapril with Moxonidine}

\author{
Zumrad Ergasheva1, Bustanov Sherzodbek2 ${ }^{2}$, Bakhtiyorjon Jurabaev ${ }^{3}$, \\ Mamurjon Turgunov ${ }^{4}$, Mukhayyo Akhmatokhunova ${ }^{5}$
}

'PhD, Docent, Head of the Department of 2nd-Preparation of General Practitioners, Andijan State Medical Institute, Andijan, Uzbekistan; ${ }^{2}$ Assistant, Department of 2nd-Preparation of General Practitioners, Andijan State Medical Institute, Andijan, Uzbekistan; ${ }^{3} \mathrm{PhD}$, Docent, Department of and-Preparation of General Practitioners, Andijan State Medical Institute, Andijan, Uzbekistan; ${ }^{4}$ Senior lecturer, Department of Pharmacology and Clinical Pharmacology, Andijan State Medical Institute, Andijan, Uzbekistan; ${ }^{5}$ Assistant, Department of Pharmacology and Clinical Pharmacology, Andijan State Medical Institute, Andijan, Uzbekistan.

\title{
ABSTRACT
}

Introduction: Treatment of arterial hypertension in type 2 diabetes mellitus patients is complex and at the same time, according to our data, possible and/or controlled process. For example, the use of combined antihypertensive therapy of enalapril with moxonidine is effective in the treatment of arterial hypertension in patients with type 2 diabetes, which has a positive effect on the dynamics of catecholamine excretion and 3,4-dioxyphenylalanine, monoamine oxidase activity, significantly reduces the level of Malone dialdehyde in serum.

Aim and Objective: After combined hypotensive therapy with moxonidine, we observed a more pronounced statistically significant decrease in daily excretion of CA and DOFA, with values of these indicators approaching those of the control group.

Result: Thus, after treatment with moxonidine, there was a significant decrease in SBP by $28.5 \%, \mathrm{DBP}$ by $11.2 \%(\mathrm{P}<0.001)$, possibly due to suppression of the SAS functional activity.

Key Words: Type 2 diabetes with arterial hypertension, Catecholamine excretion, Monoamine oxidase, Dopamine

\section{INTRODUCTION}

The appearance of new antihypertensive agents has not led to an increase in the frequency of achieving the target AP level in AG monotherapy. ${ }^{1-3}$ This fact is caused by the emphasis on combined therapy of AG. When choosing a drug for combined therapy of HA it is necessary to take into account the presence of risk factors, lesions of target organs, and associated clinical conditions. ${ }^{4,5,6}$ It has been revealed that certain antihypertensive medications of arterial pressure reduction can also influence metabolism. Mohsonidin, sympatholytic, and agonist of imidazoline receptors of the central nervous system is an effective drug used to treat arterial hypertension. ${ }^{5,6}$ Several clinical studies have shown the efficacy of moxonidine in treating AG, which was comparable with the efficacy of other modern antihypertensive drugs. Clinical studies presented in foreign literature indicate AD correction and cardioprotective effect when using this drug. ${ }^{7,89}$ There are also data on the reduction of insulin resistance when using this drug. ${ }^{10,11}$

\section{MATERIAL AND METHODS}

This subgroup - B consisted of 20 patients who also received traditional treatment, consisting of diet (table 9), sugar-reducing therapy, antioxidants (Berlithione 600 units per day), in addition to hypotensive therapy (enalapril in a dose of $10 \mathrm{mg}$ per day) received moxonidine (physiotensis, Solvay Pharma) in doses of 0.2-0.4 mg during 12 weeks.

\section{Corresponding Author:}

Dr. Zumrad Ergasheva, PhD, Docent, Head of the Department of 2nd-Preparation of General Practitioners, Andijan State Medical Institute, Andijan, Uzbekistan.

ISSN: 2231-2196 (Print) ISSN: $0975-5241$ (Online)

Received: 20.06 .2020

Revised: 10.07 .2020

Accepted: 05.08 .2020

Published: 22.08 .2020 


\section{RESULTS}

After combined hypotensive therapy with moxonidine, we observed a more pronounced statistically significant decrease in daily excretion of CA and DOFA, with values of these indicators approaching those of the control group. Thus, the excretion of total A decreased by $20.4 \%$ (1.2 times), HA - by $25.6 \%$ (1.3 times), YES - by $8.9 \%$ (1.1 times), DOFA - by $25 \%$ (1.25 times) $(\mathrm{P}<0.01-0.001)$. There was also a normalization of ratios of SCs, their precursors, and metabolites (Figures 1-3).

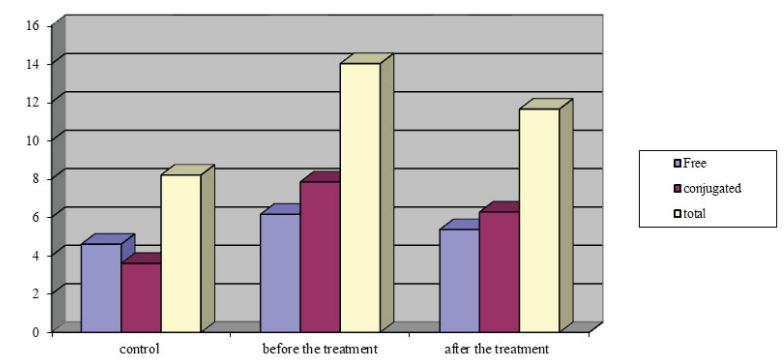

Figure 1: Daily adrenaline excretion in healthy and type 2 diabetes patients in combination with hypertension (subgroup B) before and after treatment with combined antihypertensive therapy.

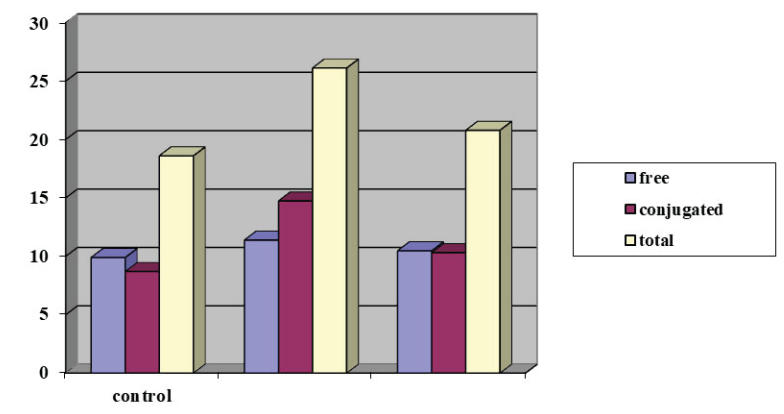

Figure 2: Daily excretion of norepinephrine in healthy and patients with type 2 diabetes in combination with hypertension (subgroup B) before and after treatment with combined antihypertensive therapy.

We also noted a more significant increase in MAO activity by $27.5 \%(1.4$ times $)(\mathrm{P}<0.001)$ about the indices of the initial level and the approach of these indices to the values of the control group (Fig. 3).

The results of the analysis of LPO processes showed that there is a significant decrease in the secondary products of LPO - MDA, the level of which decreased from $6.82 \pm 0.44$ $\mathrm{nmol} / \mathrm{ml}$ before treatment to $4.43 \pm 0.28 \mathrm{nmol} / \mathrm{ml}$ after treatment, which was 53, 8\% (1.54 times). Post-treatment MDA values in this subgroup were significantly close to those in the control group.

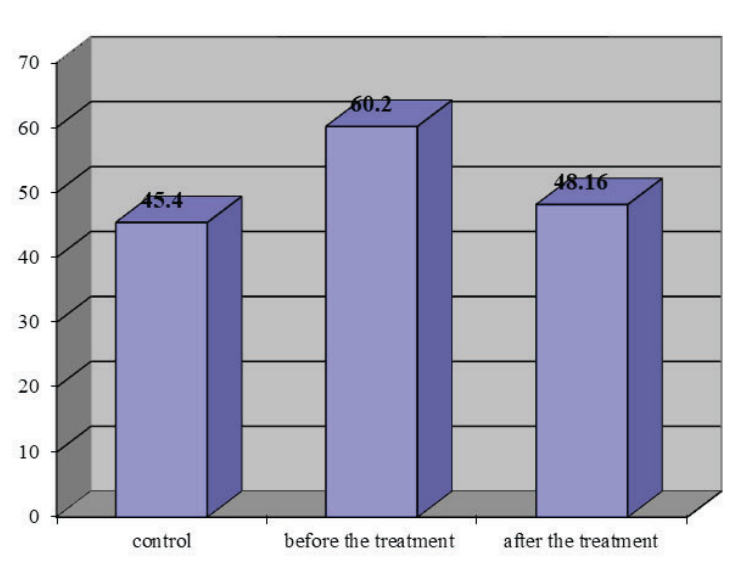

Figure 3: Daily excretion of DOPA in healthy people and patients with type 2 diabetes in combination with hypertension (sub-group B) before and after treatment with combined antihypertensive therapy.

Changes in all parameters of the lipid profile in subgroup B were statistically significant, except HDL cholesterol. The results of the treatment in subgroup B were characterized by a more significant decrease in the lipid spectrum of blood, so the level of total cholesterol decreased by $22.2 \%(1.23$ times) $(\mathrm{P}<0.001)$, there was a decrease in LDL cholesterol by $30.7 \%$, (in 1,31 times) $(\mathrm{P}<0.001)$. The levels of cholesterol VLDL, TG is $14.4 \%$ (1.14 times) and $14.9 \%$ (1.15 times) less, respectively, similar indicators before treatment $(\mathrm{P}<0.01-0.001)$. The atherogenic index is $35.1 \%(1.35$ times) $(\mathrm{P}<0.01)$, lower than the indicators of this subgroup of patients before treatment. The ratio of LDL cholesterol / HDL cholesterol decreased by $39.4 \%$ (1.39 times). The level of HDL increased by $6.5 \%(\mathrm{P}>0.05)$ about the indicators before treatment. In this regard, moxonidine, which suppresses the activity of the sympathoadrenal system and antioxidants that increase beta-oxidation of free fatty acids, act as synergists.

The average blood glucose level before treatment was $11.4 \pm$ $0.74 \mathrm{mmol} / \mathrm{L}$, and after treatment, $9.26 \pm 0.65 \mathrm{mmol} / \mathrm{L}$, i.e. the indicator after treatment decreased by $20.3 \%(\mathrm{P}<0.01)$.

Our studies have shown that a significant change in the LPO system immediately affects the SAS activity, which was expressed by a decrease in the daily excretion of adrenaline, norepinephrine, dopamine, DOPA, an increase in the level and improvement of the catalytic activity of MAO and the level of glucose in the blood. The indicators were sharply close to the values of the control group.

More clinically significant for assessing the effectiveness of antihypertensive therapy is the normalization of blood pressure, especially in patients with type 2 diabetes (Table 1 ). 
Thus, after treatment with moxonidine, there was a significant decrease in SBP by $28.5 \%$, DBP by $11.2 \%$ ( $<<0.001)$, possibly due to suppression of the SAS functional activity

Table 1: SBP, DBP and glucose indices in subgroup B during treatment

\begin{tabular}{|c|c|c|}
\hline \multirow[t]{2}{*}{$\mathrm{AH}$ in $\mathrm{mm}$} & \multicolumn{2}{|c|}{ Subgroup B $(\mathrm{n}=20)$} \\
\hline & $\begin{array}{l}\text { Before the } \\
\text { treatment }\end{array}$ & $\begin{array}{l}\text { After the } \\
\text { treatment }\end{array}$ \\
\hline SBP & $164.5 \pm 3.11$ & $128.0 \pm 1.28^{*}$ \\
\hline DBP & $94.5 \pm 1.74$ & $85.0 \pm 0.98^{*}$ \\
\hline Glucose, $\mathrm{mmol} / \mathrm{L}$ & $11.4 \pm 0.74$ & $7.26 \pm 0.65^{*}$ \\
\hline
\end{tabular}

Note: ${ }^{*}-\mathrm{p}<0.001$

Combined antihypertensive therapy with moxonidine at a dose of $0.02-0.04 \mathrm{mg} /$ day was well tolerated by patients. Not a single case of drug withdrawal due to unwanted side effects has been reported. 2 patients had a headache and dry mouth, which disappeared after a week and did not require discontinuation of the drug.

Thus, the addition of an imidazoline receptor agonist moxonidine (Physiotenza) to combination therapy in patients with type 2 diabetes seems promising, causes the desired improvement in the condition and is the drug of choice for this category of patients. ${ }^{12}$

Clinical example: patient N. Makhkamov, born in 1950, case history No. 5793/169, was admitted to the 6th therapeutic department of the AGMI clinics on 23.03.2005, was discharged on 02.04.2005.

Clinical diagnosis: Diabetes mellitus type 2, moderate, stage of decompensation. Donkey: Diabetic angiopathy of the lower extremities of the II stage, polyneuropathy of the I stage, periodontosis, retinopathy of the I stage, hepatosis. ${ }^{15-18}$

SOP: Hypertension stage 2, AH stage 2, risk of stage 3.

Complaints at admission: thirst, frequent urination, headaches, palpitations, pains and numbness in the legs, a feeling of "creeping", chilliness in the lower extremities, loss and loosening of the teeth. ${ }^{13-18}$

Anamnesis: Considers himself ill for 3 years, has repeatedly undergone a comprehensive examination and inpatient treatment. The disease is associated with stress. He takes hypoglycemic drugs (maninil, diabeton). For 8 years, he has been suffering from arterial hypertension, does not take antihypertensive drugs (enam, berlipril) regularly. ${ }^{19-22}$

Genealogical history: not burdened.

Twice a year he receives inpatient treatment for the disease. He takes sugar-reducing drugs and other metabolic drugs (Mildronate, Riboxin, ATP, etc.). ${ }^{23}$ During the last week, the patient's state of health worsened, increased dry mouth, thirst, increased urination, more frequent headaches, palpitations, dizziness, and therefore, the patient was hospitalized in the 6th therapeutic department of the AGMI clinics. ${ }^{24,25}$

Objectively: General condition of moderate severity. Consciousness is clear. Skin and visible mucous membranes of normal colour. The subcutaneous fat is overdeveloped. The patient's height is $170 \mathrm{~cm}$, weight $100 \mathrm{~kg}, \mathrm{BMI}=34.6$. Vesicular breathing in the lungs. The boundaries of the relative dullness of the heart are expanded to the left. Heart sounds are rhythmic, sharply muffled, the accent of the II tone on the aorta, systolic murmur at the apex. Pulse 90 beats per minute, rhythmic, full. Blood pressure 170/90 mm Hg. Art. Tongue dry, white-coated. The abdomen is soft, b / painful. Liver at the edge of the costal arch.

Chest fluoroscopy: pulmonary fields without features. Increased left ventricular arch.

ECG: sinus tachycardia, the horizontal position of the electrical axis of the heart, signs of left ventricular hypertrophy.

Blood test: $\mathrm{Hb}-100 \mathrm{~g} / 1$; er $-3.7 \times 1012 ;$ c.p. -0.8 ; L 5.8x109; ESR $-9 \mathrm{~mm} / \mathrm{h}$

Urine analysis: protein - abc., Ep- 1-2-3 in the n / a; L -1-2-1 in $\mathrm{p} \backslash \mathrm{h}$; uric acid salts.

Coagulogram: PTI 80\%; tolerance to heparin 5'; recalcification of plasma $175^{\prime \prime}$; thrombotic 5; fibrinogen according to Rutberg $3125 \mathrm{mg} / \mathrm{l}$.

Biochemical blood test: total bilirubin. $-7.8 \mathrm{mmol} / \mathrm{L}$, direct-abs., Not direct $-7.8 \mathrm{mmol} / 1$, blood glucose $-7.5 \mathrm{mmol}$ / 1, creatinine - $85 \mathrm{mmol} / 1$, sugar $13.1 \mathrm{mmol} / 1$.

Blood lipid spectrum: total cholesterol-7.4 mmol / 1, LDL cholesterol - $5.6 \mathrm{mmol} / \mathrm{1}$, HDL cholesterol - $0.9 \mathrm{mmol} / 1$, VLDL cholesterol - $0.9 \mathrm{mmol} / 1$, TG - $2.1 \mathrm{mmol} /$ 1, LDL-C / HDL-C - 6.22 units, IA-7.2 units.

Ultrasound: Hepatosis.

On the first day of admission to the clinic, the patient underwent a comprehensive examination of the daily excretion of catecholamines in the urine, determination of the activity of monoamine oxidase, and the level of malondialdehyde in the blood serum.

The results of the analyzes showed an increased level of daily excretion of CA and DOPA in the urine about the average values of the control group and the group of normotensive type 2 diabetes patients. Thus, there was an increase in the excretion of total A by $35.38 \%$, and total AN by $43.11 \%$.

As a result of the study, there is a slight increase in the excretion of total DA by $9.84 \%$. The daily excretion of DOPA is increased by $19.82 \%$. Along with this, a decrease in the DA / DOPA ratio by $19.6 \%$ relative to the control was also noted, 
which may indicate the inhibition of DA biosynthesis. Indicators of the ratio HA / DA exceeded the indicators of the control group by $29.3 \%$. The A / HA ratio was $4.6 \%$ lower than that of the control group. All this testifies to the impairment of CA biosynthesis from precursors. MAO activity was reduced by $57.1 \%$. The MDA level is $36.4 \%$ higher than the indicators of the control group (Table 2.).

Table 2: Daily excretion of CA and DOPA in the urine, MAO activity and MDA level in the serum of the patient Makhkamova N., case history No. 5793/169

\begin{tabular}{|c|c|c|c|c|}
\hline $\mathrm{CA}$ & Fractions & $\begin{array}{l}\text { On the } \\
\text { and day of } \\
\text { admis- } \\
\text { sion }\end{array}$ & $\begin{array}{l}\text { After } 12 \\
\text { weeks of } \\
\text { treatment } \\
\text { Control } \\
\text { group }\end{array}$ & $\begin{array}{c}\text { Control } \\
\text { group } \\
(\mathbf{n}=15)\end{array}$ \\
\hline \multirow[t]{3}{*}{$\mathrm{E}$} & Free & 6.03 & 5.25 & 4.6 \\
\hline & Conjugated & 5.07 & 4.06 & 3.6 \\
\hline & Total & 11.1 & $9 \cdot 30$ & 8.2 \\
\hline \multirow[t]{3}{*}{ NE } & Free & 6.6 & 6,07 & $9 \cdot 9$ \\
\hline & Conjugated & 20.02 & 14.02 & 8.7 \\
\hline & Total & 26.62 & 20.09 & 18.6 \\
\hline \multirow[t]{3}{*}{ DA } & Free & 149 & 146.02 & 152.0 \\
\hline & Conjugated & 167 & 143.62 & $135 \cdot 7$ \\
\hline & Total & 316 & 289.64 & 287.7 \\
\hline \multicolumn{2}{|c|}{ Dopa } & $54 \cdot 4$ & $43 \cdot 5^{2}$ & $45 \cdot 4$ \\
\hline \multicolumn{2}{|c|}{$\mathrm{E} / \mathrm{NE}$} & 0.42 & 0.46 & 0.44 \\
\hline \multicolumn{2}{|c|}{$\mathrm{NE} / \mathrm{DA}$} & 0.084 & 0.069 & 0.065 \\
\hline \multicolumn{2}{|c|}{ DA/DOPA } & 5.81 & 6.66 & 6.34 \\
\hline \multicolumn{2}{|c|}{ MAO (unit/ext) } & 0.03 & 0.045 & 0.07 \\
\hline \multicolumn{2}{|c|}{ MDA (nmol / ml) } & $4 \cdot 5$ & 2.93 & $3 \cdot 3$ \\
\hline
\end{tabular}

Thus, the functional state of the SAS inpatient N. Makhkamov was characterized by high hormonal activity, manifested by an increased level of A, HA, DA from precursors, and a parallel change in the coefficient ratios. The treatment was prescribed taking into account the effect on the functional state of the SAS in patients of this category.

The patient was prescribed traditional therapy for type 2 diabetes and combined antihypertensive therapy with an $\mathrm{ACE}$ inhibitor - enalapril in appropriate dosages, in combination with moxonidine. As a result of the treatment, within 12 weeks, we observed a statistically significant decrease in the daily excretion of CA and DOPA about the initial values (Table 19). Thus, the excretion of total A decreased by $19.33 \%$ (1.19 times), AN - by $32.5 \%$ (1.33 times), YES - by $9.10 \%$ (1.09 times), DOPA - by 25.0\% (1.25 times). MAO activity reached 0.045 units/ext, which is $50.0 \%$ (1.5 times) higher than the initial indicators. There was a decrease in LPO indicators: the level of MDA was 53.6\% (1.54 times) lower than similar indicators before treatment (Table 19).

The parameters of the lipid spectrum in this patient are shown in table 20, after the treatment, the lipid spectrum decreased. So: total cholesterol was lower by $12.4 \%$ (1.12 times), LDL cholesterol - by $16.1 \%$ (1.16 times), HDL cholesterol - by $5.9 \%$ (1.06 times), VLDL cholesterol - by $9.09 \%$ (1.1 times), TG - by $9.6 \%$ (1.1 times), IA - by $23.4 \%$ (1.23 times) lower than the indicators before treatment.

As a result of our course of treatment, the patient has a change in the main parameters: a decrease in SBP and DBP levels due to a decrease in the functional activity of the SAS, an improvement in glucose and blood lipid spectrum, an increase in monoamine oxidase activity and a decrease in lipid peroxidation processes. However, the indicators slightly exceeded the values of the control group.

From the presented data, we can conclude that the use of traditional drug therapy, including a combination of antihypertensive drugs - enalapril and moxonidine in patients with type 2 diabetes with hypertension gives a significant clinical effect. Minor differences in CA parameters from the control group, which are more significant than in the patient who received monotherapy with enalapril, indicates the clinical efficacy of the combination of enalapril with moxonidine (Table 3).

Table 3: Indicators of the blood lipid profile of the patient Makhkamova N; case history No. 5793/169

\begin{tabular}{llll} 
Indicators & $\begin{array}{l}\text { On the } \\
\text { 2nd day of } \\
\text { admission }\end{array}$ & $\begin{array}{l}\text { After 12 } \\
\text { weeks of } \\
\text { treatment } \\
\text { Control } \\
\text { group }\end{array}$ & $\begin{array}{l}\text { Control } \\
\text { group } \\
(\mathbf{n}=15)\end{array}$ \\
$\begin{array}{l}\text { Total cholesterol, } \\
\text { mmol / }\end{array}$ & 7.4 & 6.07 & $4.0 \pm 0.2$ \\
$\begin{array}{l}\text { LDL cholesterol, } \\
\text { mmol / l }\end{array}$ & 5.6 & 4.23 & $2.13 \pm 0.1$ \\
$\begin{array}{l}\text { HDL cholesterol, } \\
\text { mmol / l }\end{array}$ & 0.9 & 1.06 & $1.2 \pm 0.13$ \\
$\begin{array}{l}\text { HS VLDONP, Mol } \\
\text { / L }\end{array}$ & 0.9 & 0.78 & $0.25 \pm 0.02$ \\
TG, Mol / L & 2.1 & 1.83 & $1.3 \pm 0.1$ \\
IA, units & 7.2 & 4.7 & $2.6 \pm 0.14$ \\
\hline
\end{tabular}

So in this patient, the blood pressure indicators decreased from $170 / 100$ to $130 / 85$, which is $30.8 \%$ for SBP and $17.6 \%$ for DBP.

When studying the lipid spectrum as a result of treatment with the addition of moxonidine, a decrease in all its parameters is noted, so the level of total cholesterol after treatment decreased by $21.95 \%$, LDL cholesterol decreased by $32.45 \%$. Levels of cholesterol VLDL, TG were reduced by $15.38 \%$ 
and $14.7 \%$, respectively, in the same parameters before treatment. The atherogenic index was reduced by $53.2 \%$ about the indicators before treatment. The ratio of LDL cholesterol / HDL cholesterol was 3.9 and was lower by $59.0 \%$. The level of HDL was increased by $17.8 \%$ of the parameters of this patient before treatment (Table 3).

As a result of the course of treatment, the patient shows a change in the main parameters: a decrease in the functional activity of the SAS, an improvement in the blood lipid spectrum, an increase in monoamine oxidase activity, and a decrease in lipid peroxidation processes. Indicators of the studied parameters of this patient after combined antihypertensive treatment with moxonidine practically did not differ from the values of the control group.

From the presented data and taking into account the literary background. ${ }^{13-15}$ It can be concluded that the addition of moxonidine to the combination therapy of hypertensive patients in combination with type 2 diabetes leads to a decrease in systolic and diastolic blood pressure, due to a decrease in SAS activity. Also, the inclusion of moxonidine promotes a decrease in metabolic risk factors, which gives a certain clinical effect and it can be used as the drug of choice in the combination therapy of hypertension in patients with type 2 diabetes.

\section{DISCUSSION}

According to our data, the combination therapy of enalapril with moxonidine gives a favourable (decrease in blood glucose in every fifth patient) metabolic effect (increases the sensitivity of tissues to insulin), leads to more significant changes (normalization of the functional activity of SAS and LPO processes). In patients with type 2 diabetes with hypertension, significant violations of the functional activity of the SAS were revealed, manifested in the activation, mainly of the hormonal link (clinically, there is a pronounced improvement in the general condition, metabolic blood parameters). In parallel, a pronounced decrease in the catalytic properties of MAO was established with the activation of lipid peroxidation processes. According to our hypothesis, the reason for the low activity of MAO is the excessive intensification of LPO processes. It has been proven that not only hyperglycemia but also hyperinsulinemia is involved in the mechanisms of increased oxidative stress in diabetes. Hyperglycemia with an increase in the rate of autooxidation of glucose leads to the formation of free radicals. Hyperinsulinemia activates SAS and the amount of catecholamine-induced formation of free radicals, and through a catecholamine-induced increase in NEFA, the formation of free radicals also increases and the level of glutathione decreases. Confirming the existing literature data, we suggest, possibly, that prolonged lipid peroxidation leads to the activation of the functional state of the
SAS, which in turn activates LPO itself, thereby creating a vicious circle showing the relationship and interdependence of these two systems.

The development of hypertension correction in type 2 diabetes is explained as follows: hyperactivation of SAS (activation of mechanisms regulating blood pressure level) $\rightarrow$ impaired HA metabolism $\rightarrow$ pronounced tissue hyper-sympathicotonia $\rightarrow$ sympathetic stimulation of the heart, blood vessels and kidneys $\rightarrow$ hypertension $\leftrightarrow$ it is advisable to use drugs that reduce it (SAS) activation $\rightarrow$ combined AHT, together with an antioxidant, normalizes the excretion of CA and their metabolic precursor DOPA, MAO activity and LPO processes $\rightarrow$ this treatment tactic can be recommended as the basis of pathogenetic therapy in the treatment of AHPSD2.

\section{CONCLUSIONS}

The inclusion of combined antihypertensive therapy with ACE inhibitors with an imidazoline receptor agonist moxonidine in the basic therapy of type 2 diabetes patients with AH leads to an improvement in both the clinical manifestations of the disease and the indicators of SAS, blood lipid spectrum and LPO system. After combined AHT with antioxidants (vitamin E, $\alpha$-lipoic acid), it was noted:

1) Significant increase in MAO activity (1.4 times $p$ $<0.001)$;

2) A trend towards a decrease in the level of total cholesterol, TG and LDL cholesterol and an increase in the content of HDL;

3) Moxonidine (with a favourable metabolic effect) suppressing the activity of SAS and antioxidants that increase the beta-oxidation of free fatty acids act as synergists;

4) A significant decrease in the content of secondary products of LPO processes - malonic dialdehyde (1.54 times, $\mathrm{p}<0.001$ );

5) The level of blood pressure is below $140 / 90 \mathrm{~mm} \mathrm{Hg}$. was noted in $80 \%$, and a decrease in blood pressure below 130/90 mm $\mathrm{Hg}$ in $45 \%$ of patients with type 2 diabetes with hypertension.

\section{Acknowledgement: None}

Conflict of interest: None

Source of Funding: None

\section{REFERENCES}

1. Bravi MC, Armiento A, Laurenti O, et al. Insulin decreases intracellular oxidative stress in patients with type 2 diabetes mellitus. Metabolism. 2006;55(5):691-5.

2. Bruce DG, Chisholm DJ, Storlien LH, et al. The effects of sympathetic nervous system activation and psychological stress on glucose metabolism and blood pressure in subjects with type 
2 (non-insulin-dependent) diabetes mellitus, Diabetologia. 1992;35(9):835-43.

3. Cakatay U. Protein oxidation parameters in type 2 diabetic patients with good and poor glycaemic control, Diabetes Metab. 2005;31(6):551-7.

4. Campbell RK, White JR Jr. More choices than ever before: emerging therapies for type 2 diabetes, Diabetes Educ. 2008;34(3):518-34.

5. Clow F., Patel S., Najafi M., et al. the cortisol response to physiological challenge is preceded by a transient rise in endogenous inhibitor of monoamine oxidase, Life Sci.1997; 61(5):567-575.

6. Daly PA, Landsberg L. Hypertension in obesity and NIDDM. Role of insulin and sympathetic nervous system, Diabetes Care. 1991;14(3):240-8.

7. Desir GV. Regulation of blood pressure and cardiovascular function by renalase, Kidney Int. 2009;76(4):366-70.

8. Djordjevic J., Jasnic N., Vujovic P., et al. Distinct and combined effects of acute immobilization and chronic isolation stress on MAO activity and antioxidative protection in the heart of normotensive and spontaneously hypertensive rats, J Anim Physiol Anim Nuter 2011;19(6): 233-241. DOI: 10.1111/j.14390396.2010.01122.x.

9. Eguchi K, Hoshide S, Ishikawa J, et al., Cardiovascular prognosis of sustained and white-coat hypertension in patients with type 2 diabetes mellitus. Blood Press Monit. 2009;13(1):15-20.

10. Friedwald WT, Levy RI, Fredrickson DS. Estimation of the concentration of low-density lipoprotein cholesterol in plasma, without the use of the preparative ultracentrifuge, Clin Chem, 1972.- Vol. 18.- P. 499-502.

11. Fouillioux C, Contreras F, Lares M, et al. Metabolic and hemodynamic markers of endothelial dysfunction in patients with hypertension and patients with type 2 diabetes during the cold pressor test, Am J Ther. 2008 Jul-Aug;15(4):389-96.

12. Gavin JR 3rd. Reducing global cardiovascular risk in patients with type 2 diabetes mellitus J Am Osteopath Assoc. 2008 ;5(3): S14-9.

13. Gordon LA, Morrison EY, McGrowder DA, et al. Effect of exercise therapy on lipid profile and oxidative stress indicators in patients with type 2 diabetes, BMC Complement Altern Med. 2008 May 13;8:21.
14. Hart EC, Charkoudian N, Wallin BG, et al. Sex differences in sympathetic neural-hemodynamic balance: implications for human blood pressure regulation, Hypertension. 2009;53(3):571-6.

15. Hashizume K., Yamamoto A., Ogihara t. Free and total dopamine in human plas, Effect of posture, age and some pathophysiological conditions, Hypertens res 1995; 18(1):205-S207.

16. Heim A, Feihl F, Waeber B. [ADVANCE: a morbidity mortality study of diabetes and hypertension] / Rev Med Suisse. 2008 ;4(139):28,30, 32-33.

17. Hong S, Adler KA, Von Känel R, et al. Prolonged platelet activation in individuals with elevated blood pressure in response to a moderate exercise challenge, Psychophysiology. 2009;46(2):276-84

18. Howes LG. The effects of lipid-lowering drug therapy on cardiovascular responsiveness in type 2 diabetic patients, Diabetes Obes Metab. 2006;8(1):8-14.

19. Huggett RJ, Scott EM, Gilbey SG. Impact of type 2 diabetes mellitus on sympathetic neural mechanisms in hypertension, Circulation. 2003 Dec 23;108(25):3097-101.

20. Jensen J., Lai Y.C. Regulation of muscle glycogen synthase phosphorylation and kinetic properties by insulin, exercise, adrenaline and role in insulin resistance, Arch.Physiol.Biochem 2009; 115(1):13-21.

21. Israelian Z, Szoke E, Woerle J, et al. Multiple defects in counterregulation of hypoglycemia in modestly advanced type 2 diabetes mellitus, Metabolism. 2006 May;55(5):593-8.

22. Ito K, Hirooka Y, Sunagawa K. Acquisition of brain Na sensitivity contributes to salt-induced sympathoexcitation and cardiac dysfunction in mice with pressure overload, Circ Res. 2009;104(8):1004-11.

23. Kedziora-Kornatowska KZ, Luciak M, Blaszczyk J, Pawlak W. Lipid peroxidation and activities of antioxidant enzymes in erythrocytes of patients with non-insulin-dependent diabetes with or without diabetic nephropathy, Nephrol Dial Transplant. 1998 ;13(11):2829-32.

24. Kruger DF. Exploring the pharmacotherapeutic options for treating type 2 diabetes, Diabetes Educ. 2008; 34(3):60S-65S.

25. Lenzen S. Oxidative stress: the vulnerable beta-cell, Biochem Soc Trans. 2008;6(3):343-347. 